\title{
Os ribeirinhos da floresta amazônica: formação humana e emancipação nas bordas do colonialismo - Breves, PA, Brasil ${ }^{1}$
}

\author{
The riverside people from the amazon forest: human formation and \\ emancipation on the edge of colonialism - Breves, PA, Brazil
}

Eliane Miranda Costa

Doutora em Antropologia - UFPA

Professora da Universidade Federal do Pará - UFPA

elianec@ufpa.br

Resumo: O artigo tem como objetivo apresentar reflexões acerca da formação humana e a emancipação de ribeirinhos no arquipélago de Marajó (PA). Um grupo social que para preservar o modo de vida e a permanência no território, lutaram pela criação de uma reserva extrativista, a Resex-Mapuá. Fazendo uso da metodologia da História Oral, procuramos conhecer esse processo como prática formativa/educativa e emancipatória. Entre os resultados obtidos, a partir de uma análise qualitativa, destaca-se a luta pela terra e a Resex como táticas política e simbólica com capacidade educativa e emancipatória, importante para ajudar a questionar a estrutura hegemonica colonial que os povos tradicionais da Amazônia brasileira foram submetidos ao longo da história.

Palavras-chave: Identidades culturais; patrimônio; território; Resex-Mapuá.

Abstract: The article deals with human formation and the emancipation of riverside people in the archipelago of Marajó (PA). A social group that, in order to preserve their way of life and stay in the territory, strugled for the creation of an extractive reserve, Resex-Mapua. Using the methodology of Oral History, we seek to know this process as a formative / educational and emancipatory practice. Among the results obtained, from a qualitative analysis, the struggle for land and the Resex as polifical and symbolic tactics with an educational and emancipatory capacity, important to help question the colonial hegemonic structure that the traditional peoples of the Brazilian Amazon have been subjected throughout history.

Keywords: Cultural identities; heritage; territory; Resex-Mapuá.

\section{Introdução}

O texto resulta da pesquisa doutoral realizada entre 2014 e 2018 na Reserva Extrativista Mapuá (Resex-Mapuá), um território rural do município de Breves, situado no arquipélago de Marajó ${ }^{1}$, estado do Pará. Tem por objetivo apresentar reflexões sobre a formação e a emancipação social dos povos ribeirinhos a partir da relação estabelecida

1 Referida pesquisa foi desenvolvida no âmbito do Programa de Pós-Graduação em Antropologia da Universidade Federal do Pará (UFPA) tendo por objeto de estudo o modo de vida e a relação dos povos ribeirinhos com o patrimônio e a cultura material, encontrada em sítios arqueológicos. 
com o território tradicional. Os ribeirinhos caracterizam-se como um dos grupos tradicionais da América do Sul, especificamente, da Amazônia brasileira, chamados assim não por habitarem as margens dos rios, mas pela forma de organização e relação constituída com o ambiente Amazônico (MACHADO, 2011).

Apreendemos com a pesquisa que ao longo de décadas, de forma inteligível, esse grupo tem forjado diferentes saberes, práticas e tradições culturais para lidar com a dinâmica do lugar e, assim, alinhavar e costurar seus modos de viver, permanecer e coexistir no território tradicionalmente praticado (DE CERTEAU, 1998). Entre as táticas forjadas para permanecerem habitando referido território, destaca-se a criação da Resex-Mapuá, requerida pelos ribeirinhos junto ao estado, como medida para permanecerem no território mediante ameaças por parte de empresários que se intitulavam "donos do rio e região do Mapuá".

Neste texto, analisamos referida unidade e a luta perpetrada por sua criação como mecanismo político em defesa do território e, também, enquanto ferramenta educativa e emancipatória, exercício importante para refletir acerca da formação humana e a emancipação social de populações tradicionais no interior da Amazônia brasileira. Para desenvolver esse diálogo elegemos território, patrimônio, memória, diversidade e identidades culturais como categorias-chave, por entender que tais categorias na configuração desse processo são ferramentas para que o subalterno seja reconhecido, nas bordas do colonialismo como sujeito de direito.

O texto está organizado em quatro tópicos, além desta Introdução. No tópico a seguir, apresentamos os conceitos e a metodologia adotada na construção do artigo. Exercitando um olhar retrospectivo, no segundo tópico, evidenciamos a ocupação do território marajoara e amazônico, especialmente em Breves e região do Mapuá. Um processo que foi conduzido à luz da colonização, o que nos ajuda a explicar a precariedade e as mazelas sociais da Amazônia marajoara. E, finalmente, no terceiro e quarto tópicos, remetemo-nos às questões que procuram atentar para a temática em destaque. Aqui, visualiza-se a luta pelo território como tática para formar/educar e forjar uma espécie de emancipação social dos povos ribeirinhos, fundamental para, ao menos, questionar à dominação colonial. 


\title{
Formação e emancipação como objeto de estudo: conceitos e aspecto metodológico
}

O termo "formação humana" será aqui assumido como sinônimo do termo "educação", em seu sentido amplo, isto é, não reduzido à educação escolar. Com base em Rodrigues (2001, p. 240-241), entendemos que:

A formação humana resulta de um ato intencional, que transforma a criatura biológica em um novo ser, um ser de cultura. Esse ato denomina-se Educação. Em resumo: a Educação é um ato intencional imposto de fora sobre uma criatura que deve ser formada como ser humano. Sendo um ato intencional e externo, ele é desempenhado primeiramente pelos que antecedem na vida social os que estão sendo formados.

Todavia, como observa Rodrigues (2001), a educação, aliás, o processo formativo, não se reduz à formação externa, necessária, mas insuficiente. Isso porque o ato de educar/formar não é um simples exercício de reprodução, ao contrário, envolve a capacidade de o sujeito conduzir o próprio processo educativo.

Nesse sentido,

\begin{abstract}
a Educação, entendida como o processo de formação humana, atua sobre os meios para a reprodução da vida - e essa é sua dimensão mais visível e prática -, bem como coopera para estender a aptidão do homem para olhar, perceber e compreender as coisas, para se reconhecer na percepção do outro, constituir sua própria identidade, distinguir as semelhanças e diferenças entre si e o mundo das coisas, entre si e outros sujeitos. A Educação envolve todo esse instrumental de formas de percepção do mundo, de comunicação e de intercomunicação, de autoconhecimento, e de conhecimento das necessidades humanas. E propõe-se a prover as formas de superação dessas necessidades, sejam elas materiais ou psíquicas, de superação ou de reconhecimento de limites, de expansão do prazer e outras (RODRIGUES, 2001, p. 243).
\end{abstract}

Por meio da formação, o sujeito forja sua emancipação social. Este termo não tem uma única definição, justamente porque não há uma única concepção de "emancipação", pois depende das relações e interesses estabelecidos. Santos (2003) apresenta duas concepções de emancipação social, isto é, a concepção "fina" e a "espessa".

A primeira, refere-se "às lutas através das quais as formas de opressão ou de exclusão mais duras e extremas são substituídas por formas de opressão mais brandas" (SANTOS, 2003, p. 42). E a emancipação espessa "implica, não apenas a sobrevivência humana, mas também uma prosperidade - no dizer de Agnes Heller - guiadas por necessidades radicais" (SANTOS, 2003, p. 42), em que tais necessidades, para Heller 
(1976 apud SANTOS, 2003), são qualitativas, por isso, inquantificáveis, não podendo permanecer em um mundo baseado na subordinação.

No mundo moderno ocidental, em que a subordinação e a invisibilidade do outro (leia-se de povos não europeus) são meios para a manutenção do poder colonial, as reivindicações e lutas de povos tradicionais se assentam na perspectiva do que Santos (2003) chama de emancipação fina. A partir das lutas desses povos, notam-se importantes conquistas, a exemplo da permanência no território tradicional, como é o caso dos ribeirinhos, em destaque nesta pesquisa, amenizando em parte as formas de opressão.

Em Freire (2005), a emancipação social é fundamentalmente uma tarefa educacional, e tem como significado a "humanização". Para tanto, posiciona-se contrário a histórica desumanização colonial, que condenou milhares de seres humanos à condição de oprimidos. É uma tarefa educacional, justamente porque, por meio da educação os oprimidos, além de se entenderem sujeitos históricos sociais, terão condições de proferir a palavra, ou seja, ter e assumir suas vozes, suas histórias e memórias, e assim, lutar por seus direitos (FREIRE, 2005).

Santos (2003) e Freire (2005) nos permitem, assim, entender que a emancipação social é condição para conquistas de direitos, o que implica questionar e fazer resistência à violência, à exploração e à dominação colonial. Na particularidade deste estudo, emancipação social está sendo entendida como elemento de mobilização e reivindicação por parte dos povos ribeirinhos, a fim de questionarmos a subalternidade histórica e dar visibilidade a suas demandas no espaço público.

No configurar desse entendimento, faz-se necessário apreender que os "povos tradicionais" não são seres com identidades estáticas, arcaicos e sem futuro, como o pensamento abissal quis impor (SANTOS, 2010). Ao contrário, são coletivos em constante ressignificação, que têm resistido à hegemonia do capitalismo ocidental, e feito da "tradição" tática de resistência à dominação e exploração colonial (DE CERTEAU, 1998), bem como elemento formativo e emancipatório.

Hagino e Quintans (2015) observam que a categoria "tradicional" se constitui pauta na luta pelo reconhecimento jurídico do direito estatal desses povos para permanecerem no território ocupado. O reconhecimento estatal, por meio de leis específicas, é, conforme as autoras, critério fundamental para a emancipação. Como exemplo legal, no Estado Brasileiro, destaca-se a Convenção 169 da Organização Internacional do Trabalho (OIT), sancionada pelo Decreto legislativo no. 143/2002 e a Constituição Federal de 1988, entre outros.

A Convenção 169 deu visibilidade ao direito dos povos tradicionais, assim como a questão da diversidade cultural. Fenômeno que consideramos indispensável para que 
os povos subalternos, ainda que de forma fragmentada, sejam vistos como sujeitos de direitos. O reconhecimento da diversidade cultural contribui com a constituição de um campo jurídico do direito étnico, e isso pode ser traduzido como condição para valorizar a tradição cultural como mecanismo de ressignificação de práticas e saberes na relação com o território e os demais grupos.

A Constituição Federal de 1988 (CF/1988), embora mantenha a lógica da globalização hegemônica, contribui para fortalecer a diversidade cultural, na medida em que reconhece os indígenas e quilombolas como sujeitos de direitos. Em relação aos demais povos tradicionais, como os ribeirinhos, esta Constituição, em meio à contradição, possibilitou a tais grupos firmar o reconhecimento do direito à diferença e à existência de direitos étnicos, importante para garantir a permanência ao território tradicionalmente ocupado (ALMEIDA, 2004).

Território é aqui interpretado não apenas como espaço geográfico, mas como lugar de vida, história e memória. Isso mostra que território é o lugar onde os ribeirinhos desenvolvem seus costumes, habitus (BOURDIEU, 1989), ou melhor, é o espaço em que esse coletivo se produz material, cultural, espiritual e simbolicamente. Nesse processo, a cultura é um artefato social que envolve significados do modo de ser, viver, trabalhar e habitar. Em outras palavras, um processo que integra elementos e acontecimentos expostos e dispostos em uma intensa rede de disputas e produção de significações, tanto herdadas pelos ancestrais como tecidas cotidianamente na relação com o ambiente e os demais grupos (BARTH, 2000).

Nessa dinâmica, a identidade, não em sentido único, mas plural, é forjada pelos indivíduos. Como argumenta Hall (2011), a identidade deve ser entendida como identificação cultural, exatamente por não haver uma única identidade, mas, identidades, urdidas por uma multiplicidade de elementos nas diferentes e diversas realidades costuradas.

No contexto dos povos da floresta, suas identidades têm relação com o ambiente, as simbologias, cosmovisões que alicerçam seu modo de vida. A identidade é, nessa perspectiva, a responsável pelos laços de pertencimento e construção da memória do lugar. É critério para o reconhecimento dos povos tradicionais como sujeitos de direito ao território, entendido como patrimônio, que na lógica da política estatal cabe aos povos tradicionais proteger, por meio das Unidades de Conservação (UC) (DIEGUES, 2001; ALMEIDA, 2004).

Para além dessa lógica, patrimônio é entendido aqui não no sentido romano, como propriedade privada ou ainda como um bem nacional, mas como um bem dos ribeirinhos, que não se refere apenas à terra, incluindo suas memórias, histórias, cosmologias, 
saberes e práticas culturais. É esse patrimônio que, com a reserva extrativista, os ribeirinhos procuram defender.

Dentro desse quadro a memória merece destaque, justamente por constituir-se "a base construtora de identidades e solidificadora de consciências individuais e coletivas" (DELGADO, 2010, p. 38). A memória abarca, desse modo, saberes e práticas oralmente transmitidas em circuitos de sociabilidade; daí entendermos como importante mecanismo na luta pelo território, pois a memória fornece significados da existência e ajuda os ribeirinhos a ressignificar suas tradições e identidades culturais.

Portelli (1997) contribui com este debate, na medida em que entende ser a memória produto e experiência social cultivada por subjetividades, história, passado e futuro individual, entrelaçada ao lugar e aos grupos pertencentes. Assumindo esse aspecto, entendemos que a memória do subalterno é uma das premissas básicas para sustentar práticas e a emancipação social.

Fazendo uso da História Oral (HO) em sua perspectiva temática, e considerando a contribuição de Delgado (2010) e Portelli (2007), procuramos escutar as memórias individuais, por meio de narrativas orais capturadas com entrevistas semiestruturadas. Na realização de tais entrevistas fizemos uso de um roteiro flexível, com cinco perguntas-chave, com foco na luta e criação da Resex-Mapuá. Ao todo foram seis interlocutores, selecionados por saberem contar sobre a história do lugar, participar da luta pela criação da Resex-Mapuá, bem como se disponibilizar em contribuir com a pesquisa. Estes interlocutores estão identificados com nomes fictícios, de modo a assegurar o sigilo ético e preservar a identidade dos mesmos.

Cabe mencionar que as entrevistas foram realizadas durante a inserção em campo, entre agosto a dezembro de 2017. Todas as entrevistas foram gravadas com um gravador portátil, conforme consentimento dos depoentes, os quais, no ato da entrevista, assinaram o Termo de Consentimento Livre Esclarecido ${ }^{2}$. Tais entrevistas foram transcritas de forma literal, sendo suprimidas apenas as repetições. As análises qualitativas dessas narrativas nos permitem observar que as memórias narradas indicam ser a tradição oral mecanismo para lidar com as temporalidades específicas na relação local e global. Não é assim um fenômeno arcaico e do passado, como estabelece a racionalidade científica moderna (SANTOS, 2010), é, antes, um instrumento para potencializar o processo de formação humana e de emancipação social.

Conta-se ainda com observações etnográficas registradas no diário de campo. Seguindo Geertz (2012) adotamos a perspectiva etnográfica como tentativa de fazer

2 Resolução n ${ }^{\circ}$ 466, de 12 de dezembro de 2012, item II. 2. Disponível em: https://bvsms.saude.gov.br/ bvs/saudelegis/cns/2013/res0466_12_12_2012.html. Acesso em: 15 fev. 2021. 
uma leitura do fenômeno em estudo a partir do diálogo com as pessoas e o contexto no sentido de ampliar o entendimento acerca das relações de dominação e emancipação orquestradas na dinâmica de luta e criação da Resex-Mapuá.

\section{Heranças do passado: um território ameaçado}

Entender a Resex-Mapuá como mecanismo de luta e, por conseguinte, de formação e emancipação humana, requer, minimamente, que olhemos para o passado na tentativa de conhecermos a engrenagem histórica tecida pelo colonialismo nesse pedaço de chão amazônico, que fez do Marajó um território em disputa.

Formado por 16 municípios, o Arquipélago de Marajó, localizado no delta do rio Amazonas, caracteriza-se como uma região de contrastes, pois é rica em recursos naturais, mas com enormes mazelas sociais, fenômeno que atribui à maioria de seus municípios os piores Índices de Desenvolvimento Humano (IDH) do estado e país (BRASIL, 2013), fruto de uma longa história de exploração e dominação iniciada com a colonização portuguesa.

De acordo com Pacheco (2009), no passado, o Marajó, chamado de Ilha Grande de Joanes, foi palco estratégico para que os portugueses obtivessem êxito em seu projeto de conquista e colonização da Amazônia Oriental. O município de Breves ${ }^{3}$, localizado a $265 \mathrm{~km}$ da capital paraense, por ocupar posição estratégica dentro deste arquipélago, tornou-se importante trunfo da colonização portuguesa. Seus furos e estreitos protagonizaram ataques e resistência, tanto dos povos nativos contra os portugueses como destes contra os nativos.

Pacheco (2009) e Schaan (2009) narram em suas produções que antes da Colonização (1530-1822), viviam em terras marajoaras diversas nações indígenas, formadas por dois grupos distintos: Aruã e Nheengaíba. Aruã, no lado oriental, era falante de língua Arawak, e adentrou no Marajó 200 anos antes da Colonização. No lado ocidental, os povos Nheengaíba - significando "gente de língua incompreensível" (SCHAAN, 2009, p. 33) - eram formados por 29 nações indígenas diferentes (Anajá, Mapuá,

3 Este município tem uma área territorial de aproximadamente $9.550,454 \mathrm{~km}^{2}$ e faz limite ao Norte com os municípios de Afuá e Anajás; ao Sul, com Bagre e Melgaço; a Leste, com Anajás, Curralinho e São Sebastião da Boa Vista; e a Oeste, com os municípios de Melgaço e Gurupá. Sua população é estimada em 102.701 habitantes (IBGE, 2019), da qual metade vive no território rural. No século XVIII, chamado de Missão das Bocas, tal município foi doado pelo então Capitão General do Pará, João de Abreu Castelo Branco, aos irmãos portugueses, Manoel Fernandes Breves e Ângelo Fernandes Breves. Fato confirmado pelo rei de Portugal em 1740, quando passa a se chamar Lugar de Santana dos Breves; Vila Sant'Ana dos Breves e, também, Engenho de Breves. Em 1943, por meio do Decreto Estadual nº505, foi levado à categoria de cidade, passando a se chamar município de Breves (AMARAL, 2016). 
Pacaucaca, Guajará e outros), que podem ter migrado das regiões Andinas para o Marajó (SCHAAN, 2009).

Os indígenas Nheengaíba, em suas ligeiras canoas, e posicionados em diferentes pontos deste arquipélago com suas flechas envenenadas, contra-atacavam as investidas portuguesas, defendendo, com inteligência e astúcia, seu território e modos de ser e viver. Entre esses povos, destacam-se os Mapuá, descritos como os guerreiros mais valentes e bravos do grupo, habitantes do rio Mapuá. Estes ajudaram a conduzir uma intensa disputa que durou mais de duas décadas, e só foi encerrada com a mediação do Padre jesuíta Antônio Vieira (1608-1697), que chamava o Marajó de "Ilha dos Nheengaíba" (VIEIRA, 1735; PACHECO, 2009).

Este religioso, fazendo uso da arma da palavra sagrada, conduziu as "pazes dos Mapuá", acordo selado por este padre com o Piyé Mapuá, chefe de sete cacicados (Anaja, Aruã, Camboca, Guianá, Mamaianá, Mapuá, Piixi-Pixi), em agosto de 1659, no local hoje conhecido como Vila Amélia, no rio Mapuá ${ }^{4}$ O acordo permitiu aos portugueses livre circulação pelos Estreitos de Breves, importante para alcançarem o território de Macapá, ou Guiana Francesa, e extraírem a riqueza natural da região (SCHAAN, 2009).

Após esse acordo, os indígenas Marajoaras, além de terem suas terras assaltadas e divididas entre os fidalgos portugueses, foram escravizados, explorados, e em parte, dizimados. A violência - material, física e simbólica (BOURDIEU, 1989) - foi nessa conjuntura, transformada, como comenta Santos (2003), em um tipo de sociabilidade, com a prerrogativa de destruir a cultura do subalterno, em função do controle do território e da dominação da cultura do colonizador.

Em outras palavras, como resultado desse encontro cultural, em que prevaleceu o genocídio e o epistemicídio (SANTOS, 2010) dos povos originários da Amazônia como estratégia para concretização do projeto colonial europeu, o território e os indígenas Marajoaras foram transformados em patrimônio português. Ato que legitimou, ao longo da história, a desigualdade, a violência e a dominação deste território por parte de indivíduos (empresários) e grupos (empresas nacionais e multinacionais) que, assumindo o papel de dominantes, exploraram e exploram os bens naturais (a exemplo da madeira) e a população pobre.

Na particularidade do rio Mapuá, um capítulo dessa história, bastante presente no imaginário local, e que tem reflexo no cotidiano das famílias, ganhou corpo no final do século XIX e início do XX, com a vinda de dois portugueses e um nordestino do estado

4 Neste rio, há dois sítios arqueológicos de cemitério indígena, provavelmente dos indígenas Mapuá, por isso o rio é assim denominado. Um sítio está localizado na localidade conhecida por Vila Amélia, comunidade Nossa Senhora das Graças, e o outro sítio fica na Vila Canaticum, comunidade Perpétuo Socorro, alto rio Mapuá (COSTA, 2018). 
do Ceará . Estes homens, à base da exploração e violência, tornaram-se os principais "donos" /"coronéis" e "patrões" do rio e da floresta.

De acordo com as memórias locais, nesse período, os migrantes nordestinos, fugindo da seca no Ceará, singraram ao Mapuá com a esperança em melhores condições de vida, tal como se levava a pensar a promissora comercialização da borracha. Todavia, ao chegarem em Mapuá, eram mandados às colocações de borracha dos chamados "coronéis da borracha", que na lógica do vigiar e punir (FOUCAULT, 2004) significava instalar os migrantes em tapiris (pequenos barracos cobertos de palha e assoalhado com pedaços de árvore de açaí) no meio da floresta para viverem e trabalharem em situações extremamente precárias.

Nas lembranças de descentes desses migrantes, o trabalho era duramente vigiado e controlado pelos coronéis, que, adotando o regime do aviamento (espécie de escambo monetizado, em que os coronéis financiavam com mercadoria os seringueiros, que, por sua vez, os pagavam com a borracha, todavia, quase sempre ficavam devendo aos coronéis), mantinham os migrantes seringueiros sob seus domínios - estrutura que permaneceu e atravessou gerações.

Com a falência da economia gomífera, ganhou sustentação a exploração da madeira $^{6}$, sobretudo a partir de 1960 . Esse novo recurso foi de igual modo explorado com base no trabalho servil dos nordestinos, sobretudo de seus descendentes e de famílias nativas. Aqueles seguiram na condição de "semiescravos" dos "donos do Mapuá" (agora os descendentes dos "coronéis"), que determinavam as regras de acesso e permanência na terra.

Todavia, essa servidão não se deu, em absoluto, de forma passiva, observa-se que os ribeirinhos orquestraram estratégias para resistir às investidas do dominador. Um episódio decisivo desse enredo começou a ser tecido no começo dos anos de 2000, quando foram ameaçados de expulsão. De acordo com os relatos dos depoentes, contando com apoio do Sindicato dos Trabalhadores e Trabalhadoras Rurais (STTR-Breves), políticos locais e da Igreja Católica (Paróquia Sant'ana), os ribeirinhos conseguiram requerer

5 Entre 1850 a 1960, Breves se destacou com a produção do látex, sendo a área banhada pelo rio Mapuá a de maior produção, o que atraiu os portugueses Joaquim Nunes Hortas e Constantino Félix, bem como o cearense Antônio Joaquim, em tempos diferentes. Estes, sobretudo, Constantino Félix e Antônio Joaquim, tornaram-se os principais proprietários dessa área por meio da violência. Estrutura mantida por seus herdeiros até pelo menos a criação da Resex-Mapuá (COSTA, 2018).

6 Segundo o Plano de Desenvolvimento Territorial Sustentável do Arquipélago do Marajó, Breves foi o principal polo madeireiro da região. A produção de madeira em tora abrangia $26 \%$ da produção do estado do Pará, com destaque para a virola, o cedro e o marupá. A retirada da madeira era realizada sobretudo durante o inverno amazônico, quando o volume de água com as frequentes chuvas aumentava (BRASIL, 2007). Amaral (2016) observa que apesar de ser polo, o retorno financeiro dava-se apenas à elite, mas aos trabalhadores que retiravam a madeira no meio da floresta, restou-lhes a pobreza e a exploração. 
em 2005, junto ao Governo Federal a criação da Resex-Mapuá. Instrumento que lhes permitiu permanecer na terra tradicionalmente habitada (COSTA, 2018), e "libertar-se" das ameaças do patrão, o que nos leva a entender a reserva como elemento de luta e emancipação social, como veremos a seguir.

\section{A luta pelo território como elemento de formação e emancipação: o caso Resex-Mapuá}

O rio Mapuá é um dos rios mais extensos do município de Breves, no passado foi território dos indígenas Mapuá, o que ajuda explicar o nome atribuído ao rio e à região por ele banhada. Trata-se de um território formado por uma exuberante floresta, vários furos, igarapés e lagos, que abriga, em suas margens, aproximadamente 900 famílias agrupadas em vilas e comunidades (LEITE, 2017). Essas famílias em tese são herdeiras de pelo menos duas ancestralidades, uma milenar, a indígena, como mencionado, e uma secular, a africana, advinda de escravizados trazidos do continente no final do século XVII e, sobretudo, no século XVIII, com a criação da Companhia Geral de Comércio do Grão-Pará e Maranhão; bem como de seringalistas e seringueiros portugueses e nordestinos.

Durante percurso etnográfico, identificamos no rio e região do Mapuá a existência de 16 comunidades de pequena escala (BEZERRA, 2011), a maioria com nomes de santos católicos, como se constata: Bom Jesus, São Sebastião do Mapuá-Miri, Nossa Senhora de Nazaré do Mapuá-Miri, Rosa Mística, Nossa Senhora das Graças, conhecida por Vila Amélia, São Benedito do Mapuá, Perpétuo Socorro, Santa Rita, São José, Assembleia de Deus, São Sebastião do Canta Galo, Santa Maria, Perpétuo Socorro do Canaticum, Nossa Senhora de Nazaré, chamada de Nazaré do Jacaré, Santíssima Trindade, São José do Aramã e São Benedito do Aramã.

Verificamos que a economia local envolve a extração de palmito e madeira, e, sobretudo, a produção da farinha e do açaí (Euterpe oleracea). O açaí e a farinha são, na verdade, os principais itens da alimentação e comercialização desse grupo. Em suas práticas diárias, o rio, acessado por meio de rabetas (pequenos cascos com motor suspenso na popa), cascos e pequenos barcos, é o território que embala seu modus vivendi e operandi. A água/o rio, nessa paisagem, caracteriza-se, desse modo, como um território que possibilita aos povos da Amazônia trabalho, alimentação, lazer e sociabilidades. $\mathrm{Na}$ 
expressão de Tocantins (1973), o rio comanda a vida, ou seja, dá sentido e significado ao ser, isto é, estar, viver e fazer-se marajoara dos ribeirinhos no contexto do rio Mapuá.

Desde a guerra com os colonizadores, este rio e área por ele banhada, tem se constituído em palco de disputa e interesses políticos e econômicos, cujos grupos sociais (passando pelos indígenas, os migrantes nordestinos chegando aos ribeirinhos na atualidade) foram submetidos à exploração e violência. Dentro desse enredo, ganha destaque no imaginário local o estado de dominação iniciado em fins do século XIX e início do XX por dois portugueses (Joaquim Horta e Constantino Félix) e um nordestino (Antônio Joaquim).

As lembranças indicam que com a morte de Joaquim Horta a dominação do Mapuá ficou a cargo do nordestino Antônio Joaquim e do português Constantino Félix. Estes, intitulados de coronéis, (patente comprada, a qual ajudava os mesmos controlar os moradores), implantaram no Mapuá um forte sistema de controle das pessoas e dos recursos naturais, como se observa neste depoimento.

Eram dois comandantes, coronéis, que mandavam de um lado e outro. Aí ninguém mandava mais [...]. Ninguém podia tirar nada fora da ordem deles, tinha que ser entregue tudo para eles porque se fosse vender fora ia ser punido, ou ia para cadeia (AMARILDO, 63a, 2017).

A narrativa indica que prevalecia uma relação de paternalismo e clientelismo entre os trabalhadores e os comerciantes e proprietários de terras. Estes, fazendo uso da política do aviamento, mantinham as famílias sempre endividadas, pois a produção entregue pelos trabalhadores aos coronéis nunca atingia o valor gasto nas "cantinas" (tipo de comércio deste proprietário), com a mercadoria que precisava para manter o sustento de sua família. Isso ocorria porque quem determinava o valor da produção do trabalhador era o coronel, o qual procurava mantê-lo endividado.

Com essa estratégia, esses coronéis, principalmente o Constantino Félix e os filhos, agregaram grande parte da terra no Mapuá. Sem poder pagar a este comerciante o trabalhador era obrigado a lhes entregar a terra. Lembram os entrevistados que o filho mais velho de Constantino Félix, considerado o principal comerciante da área, na época prefeito do município, tomou a terra de muita gente, como pagamento de dívidas contraídas, com o aviamento. De acordo com Herrera (2003, p. 71), a dependência ocasionada por tal regime "[...] favoreceu a relação no sentido patrão-trabalhador [e isso] impossibilitou ações políticas que atraíssem melhorias para a região".

Nos anos de 1960, a produção da borracha foi substituída pela exploração da madeira, na época, o Mapuá, contava com várias espécies de árvores, com destaque para a virola, andiroba, cupiuba, maçaranduba, bastante comercializadas pelos proprietários 
com as diversas madeireiras que se instalaram na região. A retirada da madeira ficava por conta do trabalhador, que a entregava ao comerciante e proprietário, em troca de mercadoria. Uma relação permeada por conflitos, pois nem sempre a produção era absorvida pelo comerciante, que na condição de proprietário da terra não permitia a venda para outros, como expressa a narrativa:

\begin{abstract}
Ele (o comerciante e proprietário, chamado de patrão) dizia que essas terras era tudo dele, queria toda a produção pra ele. A gente não podia vender pra outro. Mas, às vezes, ele não queria comprar. [...]. Um dia botei minha produção no barco e fui vender pra fora [...]. Quando ia passando lá, ele mandou gente atrás de mim, me convidando pra encostar. Eu disse não [...]. Aí começou a polenga [conflito]. Até homem armado ele botou (HOZÓRIO, 53a, 2017).
\end{abstract}

Os ribeirinhos, mesmo controlados pelo comerciante-patrão, nem sempre obedeciam, como mostra esta narrativa. Obrigados a entregar a produção e, também, dividir o que coletavam como o açaí (política da meia) em muitas situações enfrentavam e desobedeciam ao proprietário. Esse conflito ficou acirrado mais ainda, segundo os interlocutores, quando o comerciante-patrão, ainda nos anos de 1970, estabeleceu acordo com a empresa Superfine Madeireira Ltda. (depois Santana Madeireira Ltda), e repassou a essa empresa de capital japonês, 98 mil hectares de terras do Mapuá. Todavia, os antigos "donos" continuaram na área, até porque a relação entre a empresa e estes era de responsabilidade mútua, isto é, a empresa comprava a madeira e o antigo dono controlava os ribeirinhos por meio da relação de subordinação, com o endividamento (CORNETTA, 2016).

No ano de 1978, a empresa fechou, e as terras voltaram para as mãos dos herdeiros de CF/1988, mas em 1999 e início dos anos de 2000, a empresa Santana Madeireira Ltda., agora com novo nome (Ecomapuá7) e gerência, retomou as terras no Mapuá. O novo diretor veio ao Mapuá alegando que a empresa agora adotava outra concepção, ou seja, seguia pelo caminho do desenvolvimento sustentável, concepção adotada no Brasil desde os anos de 1970, mas que em realidades como a deste arquipélago ainda não se ouvia falar. Situação que na compreensão de Herrera (2003) contribuiu com a perpetuação das desigualdades.

Esse autor observa que um fator central desse tipo de desenvolvimento na Amazônia é "[...] o crescimento econômico, fundamental para melhorar as condições de vida das populações regionais" (HERRERA, 2003, p. 29); mas que para isso faz-se necessário

7 Empresa florestal privada, criada em 2000 para fornecer produtos e prestar serviços na área de reflorestamento. Atua no mercado de energias renováveis, utilizando resíduos florestais, e na produção de óleos vegetais, para finalidades diversas, incluindo biocombustíveis. Para mais informações ver: www. ecomapua.com.br. 
um conjunto de políticas econômicas e sociais voltadas para elevar a renda das famílias. Outro aspecto importante é compreender as famílias ribeirinhas como importantes parceiras na proteção e conservação dos recursos (DIEGUES, 2001).

No entanto, não foi bem essa a atitude adotada pelo diretor da Ecomapuá. Este empresário fez uma reunião, chamada inclusive de "seminário", contando com a participação de estudantes da Universidade Federal do Pará (UFPA), e pesquisadores de outras instituições a fim de informar aos ribeirinhos da intenção de transformar o Mapuá em uma reserva de desenvolvimento sustentável. Nesse evento, destacou-se que os trabalhadores locais não poderiam mais explorar a madeira, o palmito e fazer a roça, principais atividades das comunidades no Mapuá, sob pena de serem punidos e expulsos do território, que agora pertencia à empresa.

Diante da ameaça, os ribeirinhos que já vinham participando do STTR-Breves e contando com orientação e apoio de políticos e instituições como a Igreja Católica, organizaram-se e fizeram frente a nova ameaça. A saída encontrada foi a de requerer a criação da Resex-Mapuá, como podemos observar na seguinte narrativa:

[...] O patrão tinha vendido a terra para o chinês, em 99. Aí em 2001 ele [o patrão] veio tomar a posse, mas com ameaça que o povo não podia tirar a madeira, não podia fazer roça [...]. Então fomos fizemos uma passeata em Breves que foi uma polêmica [...]. Entrou o sindicato, entraram outras entidades [a igreja católica e políticos] e a comunidade [...] todo tempo no apoio [...]. O advogado [do Sindicato orientou os moradores afiliados a este órgão para criar a reserva] disse vamos preparar um abaixo-assinado e mandar pra Brasília. Vamos pedir uma reserva [...] Ele preparou o abaixo-assinado e eu trouxe e levei nas comunidades e nós conseguimos 778 assinaturas e encaminhamos para Brasília [...], em 20 de maio de 2005 foi aprovada [...], criada a Resex-Mapuá [...]. Nos livramos da ameaça dele [o empresário-proprietário] e permanecemos aqui (AMARILDO, 63a, 2017).

A narrativa mostra que a criação da Resex-Mapuá foi precedida por conflitos e desafios, que desencadeou em um rearranjo político e fundiário (CORNETTA, 2016). Tudo isso exigiu dos ribeirinhos organização e articulação coletiva. Em grupo, assumiram uma postura de desobediência, cuja estratégia foi fazer suas vozes serem ouvidas. Para isso, realizaram a passeata pelas ruas da cidade de Breves, chamando a atenção de autoridades e da população local para as ameaças e problemas que enfrentavam. Com essa atitude, colocaram em evidência as relações de poder estruturada pelo capital, bem como reivindicaram espaço de ação política historicamente negado (SANTOS, 2003).

Desse modo, a luta enfrentada por este grupo para permanecer no território que tradicionalmente ocupam (ALMEIDA, 2004) deve ser entendida como luta por direitos humanos, e isso inclui o direito à saúde, à educação, à moradia, ao patrimônio, entre 
outros. A articulação política envolvendo o sindicato e a própria Igreja mostra a capacidade física e mental dos ribeirinhos para reivindicar tais direitos, bem como questionar sua condição de invisibilizados e inserir-se à sociedade (SANTOS, 2003).

A tônica coloca em relevo a possibilidade de alternativa que o subalterno pode criar para resistir à opressão colonial (tal como fizeram os indígenas Nheengaíbas quando enfrentaram os colonizadores), ainda que essa opressão não seja totalmente eliminada. Daí entender a luta e a própria criação da Resex como elementos de formação e emancipação social.

Como se observa, todo o arranjo e rearranjo político envolvido não foi algo realizado de imediato e conduzido por terceiros apenas, ao contrário, foi uma ação protagonizada pelos próprios sujeitos. Na verdade, o sindicato foi uma ferramenta importante na condução e combate ao conflito, pois, como membros desse órgão, os ribeirinhos fizeram uso da estrutura do mesmo a seu favor. Podemos dizer que houve, nesse processo, aprendizados e formação, tornando o sindicato em território educativo (RODRIGUES, 2001).

De acordo com os relatos a seguir, a conquista do território, sustentada pelo sindicato, tem reflexo na formação desses subalternos e atua como condição necessária à emancipação social.

Nós fomos pra luta, fomos pra praça, fizemos movimento. Através da informação a gente foi conseguindo se libertar, porque a gente não podia passar na boca do Mapuá com 10 fardos de farinha que era perseguido [...]. O sindicato deu suporte, e através do conhecimento [refere-se à formação escolar] que pessoas que nem eu e muitos adquiriram [...] fizemos esse grupo aí, lutamos [...], já não teve mais patrão (JOVELINO, 48a, 2017).

Com ajuda do Sindicato [...], nós começamos a lutar e nos libertamos. Liberamos o Mapuá [...]. Aí nós começamos a vender onde dava mais. Aí foi melhorando o Mapuá [...] (JOÃO, 58a, 2017).

A criação da Resex-Mapuá, para os ribeirinhos, os "libertou" dos comerciantes que se intitulavam proprietários do Mapuá e patrão das famílias ribeirinhas. Essa unidade, ao contrário das demais criadas na Amazônia, não resulta de imposição do estado, mas responde às reivindicações dos subalternos, o que faz dela instrumento político e até mesmo jurídico das comunidades para permanecerem no território que tradicionalmente habitam e praticam (DE CERTEAU, 1998; ALMEIDA, 2004).

Desse modo, sugere-seque a reserva, apesar das contradições que isso implique, exige repensarmos a lógica do capital frente à realidade desse grupo. Na verdade, tem-se 
uma ação estratégica para questionar o sistema de dominação imposto pelo capital e mantido pela política agrária do Estado Brasileiro.

Diegues (2001) nos lembra que a criação das Reservas Extrativistas (RESEX) foi uma conquista dos seringueiros para preservar os recursos naturais e o próprio modo de vida. É ainda conforme Almeida (2004) mecanismo para que os povos tradicionais possam permanecer no território habitado e praticado. Na compreensão de Acselrad (2012), as reservas podem representar a garantia de eficácia e legitimidade da conservação da natureza e sua riqueza. Mas, isso depende de interesse e perspectiva dos grupos sociais, bem como do próprio Estado.

Santos (2003) ajuda entender essa engrenagem bem no ponto em que a defende, tendo por base a perspectiva de um cosmopolitismo subalterno ${ }^{8}$, que os sujeitos subalternizados devem lutar para ter seu direito legalmente reconhecido. A luta é condição para os grupos atuarem de forma contra-hegemônica na conquista de direitos negados, como o direito de praticar e habitar no território com dignidade.

No caso da Resex-Mapuá, pode-se dizer que a luta representa a conquista do direito de permanecer na terra e acessar aos recursos e proveitos materiais necessários à garantia de existência do grupo. Entendemos que permanência e acesso a terra não tem apenas valor econômico e político, ao contrário é um processo que entrelaça, sobretudo, um poder simbólico (BOURDIEU, 1989) que está relacionado com a identidade, a memória e a história dos ribeirinhos, tecidas e urdidas desde suas ancestralidades.

\section{Após a criação da Resex-Mapuá: mudanças e permanências}

A Resex-Mapuá, criada por meio do Decreto Presidencial s./n., de 20 de maio de 2005 (Brasil, 2005), dispõe de uma área de 94.463,03 hectares, e conta com a Associação dos Moradores da Reserva Extrativista Mapuá (AMOREMA), criada nesse mesmo ano. Esta associação, presidida por um ribeirinho da comunidade Bom Jesus, em abril de 2010, recebeu o Contrato de Concessão de Direito Real de Uso (CCDR), como determina o artigo 23, III, do Sistema Nacional de Unidades de Conservação da Natureza (SNUC), aprovado em 2000.

Essa concessão refere-se a um tipo de contrato entre a União e a Associação dos Moradores, que estabelece ações de reconhecimento, demarcação e discriminação das terras públicas de domínio da União. Podemos dizer que é uma estratégia de regularização

8 Santos (2010, p. 50) adota o termo cosmopolitismo subalterno como "uma forma cultural e política de globalização contra-hegemônica", que se manifesta por meio das iniciativas e movimentos que lutam contra a exclusão social, política, econômica e cultural, frutos do neoliberalismo, fase recente do capital. 
fundiária, permeada por um processo complexo, moroso e conflitivo, que no Mapuá até então tem se reduzido aos Termos de Autorização de Uso (TAU), emitidos pela Superintendência de Patrimônio da União (SPU).

Este documento assegura, provisoriamente, às famílias o direito ao acesso e permanência no território, sob a gestão do Instituto Chico Mendes de Conservação da Biodiversidade (ICMBio). Daí dizer que nessa reserva o CCDR precisa ser um instrumento relevante, e isso inclui a necessidade de construir ações ambientais que atenda às necessidades das famílias e da preservação ecológica.

Com a Resex, como já mencionado, as famílias ribeirinhas do rio Mapuá alegam "libertarem-se" dos comerciantes-patrões e, por conseguinte, dos conflitos ambientais. Todavia, não significa que os conflitos acabaram, até porque novos problemas surgiram como antigos permaneceram. Entre as novas disputas destaca-se a falta de diálogo e a aproximação entre gestores e a população local. Os depoentes reclamaram que os gestores não dão o apoio necessário para as famílias desenvolverem o manejo dos recursos naturais como se exige.

O plano de uso da Resex, construído em 2008 com a participação das comunidades, precisa ser revisado, mas até o momento desta pesquisa a atualização não ocorreu. Nesse plano, há determinadas proibições quanto ao corte de madeira, caça de certos animais, entre outras, que para as famílias é difícil de concordar e obedecer, pois precisam trabalhar e garantir o sustento. Como comenta Santos (2003, p. 62) "[...] muitas vezes, o que está em jogo é a sobrevivência pura e simples", como parece ser o caso.

A gente continua tirando a madeira, o palmito, fazendo a farinha [...] Nós sabemos trabalhar com machado, terçado e inchada, né. Isso nós sabemos, qualquer um de nós sabe aqui. Mas, não sabe, muita gente não sabe, o que é manejo, né. Aí fica difícil né, sem ter uma pessoa pra incentivar e levar aquele negócio a sério [...]. Aí a gente continua naquilo que a gente sabe: fazer roça, fazer farinha, tirar madeira, tirar palmito, e é isso que nós estamos fazendo (FERNANDO, 58a, 2017).

Esse relato mostra que tem prevalecido o antigo modelo de exploração dos recursos. Situação que se justifica pela forma como esses homens e mulheres, ao longo de décadas, foram submetidos ao trabalho na floresta, o qual garantia o próprio sustento. Certamente, mudanças profundas são necessárias, contudo, levará um tempo para que outras práticas sejam incorporadas e desenvolvidas, como o manejo do açaí e da madeira. Para tanto, a gestão da reserva (ICMBio) precisa, além de estabelecer uma relação de diálogo e proximidade com as famílias, promover ações educativas e de 
apoio aos indivíduos, para que possam construir outro jeito de produzir, trabalhar, olhar a vida e o território.

Outro problema enfrentado diz respeito ao tamanho da área. Antes as famílias podiam caçar, pescar, fazer a roça em qualquer área. Porém, com a reserva, todos receberam o TAU, que limita o tamanho (500mt de frente e um mil de fundo) das áreas por família, e para as famílias numerosas esse tamanho é considerado pequeno para realizar suas atividades. Então, alguns moradores, não entendendo ou não querendo, invadem a área do vizinho, o que gera intrigas entre os próprios ribeirinhos, como se observa nesta narrativa:

Os conflitos entre vizinhos são muitos [...]. Tem gente que não entende as coisas, um pensa que o direito é dele o outro pensa que é dele [...]. Não respeita o conselheiro. Aí quando as pessoas vão se queixar diretamente no ICMBio, eles dizem, mas não tem o conselheiro? É o conselheiro que tem que resolver lá [...]. Então não fazem nada (ANCELMO, 45a, 2017).

O exposto deixa claro que há uma disputa interna pelo uso e apropriação dos recursos e benefícios materiais, o que analisamos como reflexo da opressão introjetada. Na expressão de Freire (2005) significa que o oprimido "hospeda o opressor em si" resultando em uma dualidade existencial que ele chama de "consciência 'hospedeira' da consciência opressora" (FREIRE, 2005, p. 37). Nessa lógica, o comportamento do oprimido é sempre prescrito. Os conflitos entre vizinhos revelam tal comportamento, isto é, os ribeirinhos, na condição de oprimidos assumem também a pauta de opressor, pois, assim como os patrões/empresários, praticam cotidianamente a opressão entre si pelo acesso e uso do território.

Daí sustentar que a emancipação desenvolvida com a Resex-Mapuá, é uma emancipação fina (SANTOS, 2003), que ameniza e/ ou substitui as formas de dominação, mantendo assim a lógica colonialista. A ruptura com a lógica opressora requer na expressão de Santos (2003) e Freire (2005) uma emancipação liberadora que transforme radicalmente a condição de oprimidos e opressores. Uma luta que só "tem sentido quando os oprimidos, ao buscar recuperar sua humanidade, que é uma forma de criá-la, não se sentem idealistamente opressores, nem se tornam, de fato, opressores dos opressores, mas restauradores da humanidade em ambos" (FREIRE, 2005, p. 33).

Cabe ressaltar que os antigos proprietários, aliás, os opressores não saíram de cena totalmente, não deixaram o território, especialmente, a empresa Ecomapuá, que em parte da área verde do Mapuá mantém um projeto de sequestro de carbono (CORNETTA, 2016). Alega que o governo não a indenizou pela posse da terra, legalmente adquirida, por isso, tem direitos de continuar operando na área. Situação que pode representar 
ameaça aos ribeirinhos, considerando a política governamental que tende tratar a floresta amazônica como celeiro do capital. Esses fatos revelam que os ribeirinhos continuam a enfrentar diferentes conflitos, porém, com a diferença de poder permanecer no território, embora a terra continue sob o domínio do Estado.

Contudo, para além dos conflitos socioambientais, nota-se ainda a violência provocada pelo uso de bebidas alcoólicas, drogas por parte da juventude, resultante da inserção de pessoas que viajam ao Mapuá para comercializar tais produtos. Segundo os depoentes, esse é um dos maiores problemas que enfrentam atualmente, porque muitos jovens, influenciados por essas drogas e más companhias, não querem mais trabalhar na roça com a família, e outras atividades. Isso pode afetar as tradições culturais futuramente.

Esse grupo tem ainda de lidar com um precário serviço de saúde que pouco atende às suas necessidades. No percurso etnográfico identificamos que os dois postos construídos pela prefeitura, tem o mínimo de equipamentos e dificilmente contam com remédios. Têm-se também problemas com a educação escolar, principalmente com a oferta do ensino. Verificamos que a maioria das escolas continua organizada em classes multisseriadas (formadas por alunos de diferentes faixas etárias e níveis de aprendizado, conduzidas por um único professor) e limitada aos anos iniciais do Ensino Fundamental.

Em termos arquitetônicos, de acordo com os relatos orais e as observações etnográficas, nos últimos anos, algumas escolas passaram a apresentar melhorias, especialmente seis escolas polos, criadas a partir da política de nucleação implementada pelo município em 2009 (CARMO, 2010). Estas escolas contam com seis salas de aula, cozinha, banheiros, sala dos professores, laboratório de informática e secretaria e ofertam Educação Infantil e o Ensino Fundamental, anos inicias e finais. Em três dessas escolas, vêm sendo ofertado, por meio do Sistema Modular de Ensino da Secretaria de Estado de Educação (SEDUC), o Ensino Médio. A oferta desse nível se reduz a uma turma em cada escola, que nem sempre conta com as aulas regularmente. Na verdade, o curso leva em média cinco a seis anos para ser concluído, e normalmente os alunos não cursam todas as disciplinas, ou estudam em uma semana, o que deveria ser em 40 dias.

Cabe pontuar como um elemento importante da educação formal no Mapuá, a criação, em 2009, da Casa Familiar Rural (CFR). Identificamos que até 2017 esta CFR foi responsável por uma formação técnica em nível fundamental e médio em regime de alternância pedagógica. Com esta formação, muitos jovens conseguiram passar em processo seletivo e acessar cursos universitários, fazendo da escola importante conquista 
e aposta para os jovens. Todavia, devido à inadimplência, a CFR não tem conseguido manter suas atividades.

O diálogo com os entrevistados e as nossas observações etnográficas nos permitem dizer que, a escola pública no Mapuá enfrenta problemas com a escassez material, ausência de aulas, rotatividade docente, entre outros. Tem ainda por desafio superar um currículo e, também, uma prática, ancorada na racionalidade urbana-capitalista que invisibiliza a cultura dos povos ribeirinhos. Mas, apesar dos problemas, há uma aposta por parte das famílias ribeirinhas na educação escolar. Na verdade, a educação escolar é vista como esperança para esse grupo construir outras possíveis vidas na floresta.

A esperança, como escreve Papa Francisco (2015) na Carta Encíclica Laudato Si, "convida-nos a reconhecer que sempre há uma saída, sempre podemos mudar de rumo, sempre podemos fazer alguma coisa para resolver os problemas". Para os ribeirinhos do Mapuá, a esperança na educação escolar pode significar a possiblidade de conquistar o direito em ter direito, de construir uma formação humana crítica, elementos essenciais para cultivar a emancipação social. E, assim, poder questionar a injustiça e desigualdade social, desenvolver uma consciência e sensibilidade ecológica em vista da proteção do ecossistema e da vida na Amazônia, como defende o pontífice na Carta citada, bem como superar a condição de oprimido, no dizer de Freire (2005).

Faz parte da dinâmica da vida entre rio e floresta o papel da Igreja, com destaque para a Igreja Católica, presente nas comunidades do Mapuá por meio das capelas. Das 16 comunidades, 15 seguem a orientação do catolicismo, adotando um/uma santo/a católico/a como padroeiro/a, como já mencionamos. Eduardo Galvão (1955, p. 43), ao referir-se ao catolicismo na Amazônia, escreve: "o catolicismo é, na sociedade rural Amazônica, uma superestrutura, uma ideologia, que se sobrepõe a crenças locais, porém por si só incapaz de responder a todas as exigências do meio".

No rio Mapuá, a Igreja Católica, como evidenciamos nas narrativas, foi uma das instituições que contribuíram com a luta pela criação da Resex, então representa não só um território para cultivar a espiritualidade, mas é, também, um espaço de formação humana e de emancipação, como se observa no seguinte excerto:

a igreja nos une como comunidade e assim a gente consegue as coisas [...] nos ajudou na luta com a Resex [...], também, conseguimos a escola, que tem o papel de ensinar nossos filhos. Eu digo assim essas duas instituições são muito importantes pra nós, pro nosso desenvolvimento (JOVELINO, 48a, 2017).

O exposto deixa claro que a presença da igreja foi fundamental para se organizarem em comunidades, definidas por eles como "unidade (bem comum) entre as famílias, influenciada pela Igreja católica, bem como pela proximidade espacial e pela ligação 
com os lugares que compõe os espaços praticados" (COSTA, 2018, p. 111). Ao mesmo tempo em que a igreja torna-se elemento indispensável na reivindicação da reserva, a Resex também se constitui ferramenta para a formação das comunidades. Pois, até a criação desta unidade verifica-se a existência de uma única comunidade.

Embora os desafios e conflitos como mencionado, a Resex tem representado mudanças no modo de vida dos ribeirinhos, o que inclui a relação com o meio ambiente, produção e consumo dos bens e interação com outros grupos. Algumas famílias, aos poucos estão sendo instruídas no processo de manejo do açaí e da madeira e isso tem refletido no aumento da produção, especialmente, do açaí. Verifica-se ainda aumento na produção da farinha e liberdade para comercializar. Dinâmica que tem permitido acesso a outros bens, como TV por assinatura, energia (gerada por motor), água gelada, viagem como frequência à cidade, celular, internet e a rabeta (casco motorizado).

Todo o enredo descrito parece indicar que a luta pelo território, ou melhor, pelo patrimônio, é condição para os ribeirinhos garantirem o uso da terra e seus recursos, como também para ter acesso a outros bens, praticarem sua cultura e espiritualidade, que orientam e explicam a relação com o passado, o presente e suas expectativas para o futuro (BARTH, 2000). Daí entendermos que a luta pelo território, não se encerra com a criação da Resex, como tática para formar e promover a emancipação social desse grupo no interior da Amazônia brasileira.

Apreendemos que para a emancipação social ser uma realidade, o direito dos povos tradicionais, violentados ao longo dos tempos, precisa fazer parte de um conjunto de direitos mais amplos, como as práticas legais, o reconhecimento do saber local e das experiências culturais. Faz-se necessário, também, romper com a lógica colonial que se reverbera nas relações internas, como fica claro com os conflitos entre o grupo. Outro fator fundamental é o reconhecimento desses povos como proprietários do território, que significa ter a posse da vida, da história, da memória, das tradições culturais, herdadas de seus ancestrais e reinventadas cotidianamente nas bordas do colonialismo.

\section{Considerações finais}

O texto mostrou que o território marajoara, com destaque para o rio Mapuá e seus recursos, vem sendo, ao longo da história, alvo de intensas disputas e interesses, incluindo a guerra com os colonizadores no século XVII, depois as colocações da borracha em inícios do século XX, e a exploração da madeira que atravessa décadas até os dias atuais. Ao longo desse processo, os povos tradicionais, em especial os ribeirinhos, que têm seu cotidiano determinado (não é um determinismo rígido, até porque esses 
povos aprenderam a lidar com a dinâmica de rio) pelas águas, vêm forjando suas formas de produzir-se, cultural, espiritual e materialmente, na floresta.

O traçado histórico permite sustentar que as desigualdades e mazelas sociais que assolam os povos do Marajó são reflexos da exploração e dominação colonial. E nesse enredo, entre as principais questões conflitivas que os povos tradicionais precisam lidar cotidianamente, está a política agrária brasileira, a qual tem feito desses povos sujeitos invisíveis e sem direitos. Daí dizer que a luta pela permanência no território desencadeada pelos ribeirinhos do/no Mapuá é uma luta pela emancipação, pois possibilita questionar a invisibilidade, historicamente costurada.

Como evidenciado neste artigo, exploração, violência e dominação do território implicou para os ribeirinhos ter suas vidas, seu tempo e trabalho controlados por comerciantes, que se tornaram proprietários por meio da espoliação de terras. Estes, na condição de "donos" do Mapuá, decidiam e agiam segundo suas próprias determinações, privando os ribeirinhos do direito de decidir pela própria vida.

Diante desse cenário, a luta pelo território que culminou na criação da Resex-Mapuá permitiu aos ribeirinhos a "liberdade". Esta apresenta-se associada à possibilidade desses sujeitos decidirem sobre o uso do território. Em outras palavras, permitiu serem "donos" de seu tempo, trabalho, decisões, memórias, histórias, tradições culturais, identidades, patrimônio, ou melhor, de suas vidas. Desse modo, a luta pelo território configura-se como importante tática política e simbólica, pelo menos, para questionar esse longo processo de exploração e dominação cultural, política, econômica e epistêmica (SANTOS, 2003).

Daí dizer que a criação da Resex-Mapuá pode ser vista como condição para repensar a problemática da política de regularização fundiária, como também criar novas possiblidades para relacionar-se com o ambiente, de modo a construir consciência e sensibilidade ecológica. Mas, para que as novas possibilidades aconteçam, faz-se necessário a contribuição de uma escola que tenha como tarefa educacional potencializar, pedagogicamente, as tradições culturais, as memórias individuais e coletivas, o patrimônio, as diversidades, identidades culturais e a autonomia, sem deixar de trabalhar as questões epocais e os conhecimentos sistematizados pela ciência no decorrer da História (FREIRE, 2005).

Cabe observar que a Resex possibilitou, mesmo provisoriamente, a redefinição de posse e uso do território e a organização social na região, com a criação de movimentos, a exemplo da organização das mulheres, as quais, a partir de então, começaram 
a participar de decisões comunitárias (são membros do Conselho da Resex lideranças religiosa e comunitária).

Com a Resex, os ribeirinhos passaram a ouvir sobre manejo da floresta, embora ainda muitos não tenham clareza sobre o que isso significa. $O$ fato é que algumas famílias instruídas pelo ICMBio aprenderam a realizar o manejo do açaí, e desde então a produção aumentou, possibilitando o acesso a outros bens, como celular, TV por assinatura, a substituição do casco pela rabeta. O celular e a rabeta podem ser caracterizados como artefatos símbolos da "liberdade", em especial dos jovens para usar o tempo, acessar o rio, ampliar a comunicação e o contato com outros grupos, ou seja, qualificar as práticas culturais e a sociabilidade entre rio e floresta (BARTH, 2000).

Nessa dinâmica social, territorial e identitária, a Igreja, a escola, a floresta, o rio, os movimentos (com destaque para a AMOREMA e o sindicato) e a própria família caracterizam-se como territórios educativos/formativos e emancipatórios dos povos ribeirinhos no rio Mapuá. Em cada um desses territórios, conhecimentos, saberes, práticas, tradições culturais e aprendizagens são forjadas, construídas, regadas e ressignificadas cotidianamente.

Esses territórios dão sentidos e significados à vida. Daí concluir que nesses territórios a formação humana e a emancipação social ganham ressonância. Pois é no encontro, na relação com outro e com o mundo, que homens e mulheres se formam, transformam-se e transformam o mundo (FREIRE, 2006). Portanto, a luta pelo território e a criação da Resex-Mapuá podem ser interpretadas como possibilidades para questionar a estrutura hegemônica colonial que os povos tradicionais da Amazônia brasileira foram historicamente submetidos. São também possibilidades de garantia da "preservação" do patrimônio material e imaterial do Marajó.

\section{Referências bibliográficas}

ACSELRAD, Henri. Mapeamentos, identidades e territórios. In: ACSELRAD, Henri. Cartografia social e dinâmicas territoriais: marcos para o debate. Rio de Janeiro: Universidade Federal do Rio de Janeiro, Instituto de Pesquisa e Planejamento Urbano e Regional, 2012. pp. 9-38.

ALMEIDA, Alfredo Wagner Berna de. Terras Tradicionalmente ocupadas: processos deterritorialização e movimentos sociais. Estudos Urbanos e Regionais, 6(1), 2004, p. 9-32. Disponível em: https:// rbeur.anpur.org.br/rbeur/article/view/102.

AMARAL, Vanessa Silva do. Instrumentos do Estado e dos Atores Sociais no uso sustentável da Reserva Extrativista Mapuá-Marajó. Dissertação de Mestrado. PPGAS, Universidade Federal do Pará, 2016.

COSTA, Eliane Miranda. Memórias em escavações: narrativas de moradores do rio Mapuá sobre os modos de vida, cultura material e preservaç̧ão do patrimônio arqueológico (Marajó, PA, Brasil). 2018. 334 f. Tese de Doutorado. Programa de Pós-graduação em Antropologia (PPGA), Universidade Federal do Pará, Belém, 2018. 
BARTH, Frederick. O guru, o iniciador e outras variações antropológicas. Rio de Janeiro: Contra $\mathrm{C}^{\prime} \mathrm{P}^{\prime}$ Livraria, 2000.

BRASIL. Constituição da República Federativa do Brasil, 1988. Disponível em: https:/ / www2. senado.leg.br/bdsf/bitstream/handle/id/518231/CF88_Livro_EC91_2016.pdf.

BRASIL. Presidência da República. Lei $n^{\circ}$ 9.985, de 18 de Julho de 2000. Regulamenta o art. 225, § 1o, incisos I, II, III e VII da Constituição Federal, instituio Sistema Nacional de Unidades de Conservação da Natureza e dá outras providências, 2000. Disponível em: http:/ / www.planalto.gov.br/ccivil_03/leis/19985.htm.

BRASIL. Senado Federal. Decreto legislativo $n^{\circ}$. 143, em 20 de junho de 2002. Aprova o texto da Convenção $n^{\circ} 169$ da Organização Internacional do Trabalho sobre povos indígenas e tribais em países independentes, 2002. Disponível em: https://www2.camara.leg.br/ legin/fed/decleg/2002/ decretolegislativo-143-20-junho-2002-458771-exposicaodemotivos-143060-pl.html.

BRASIL. Presidência da República. Decreto Presidencial s/n, de 20 de maio de 2005. Dispõe sobre a Reserva Extrativista Mapuá no município de Breves, no Estado do Pará, e dá outras providências. Diário Oficial da União. Brasília, DF., 2005.

BRASIL. Atlas do desenvolvimento Humano do Brasil, 2013. Disponível em: ttp:/ / www.br.undp. org/content/brazil/pt/home/presscenter/articles/2013/07/29/atlas-brasil-2013-rankings-e-recortes-principais-para-avalia-o-do-idhm.html.

BEZERRA, Marcia "As moedas dos índios": um estudo de caso sobre os significados do patrimônio arqueológico para os moradores da Vila de Joanes, ilha de Marajó, Brasil. Bol. Mus. Para. Emilio Goeldi. Cienc. Hum. 6(1), 2011, p. 57-70.

CARMO, Eraldo Souza. Processos educacionais e as estratégias de municipalização do ensino no município de Breves no arquipélago do Marajó. 2010. Dissertação de Mestrado. Núcleo de Altos Estudos Amazônicos, Programa de Pós-Graduação em Desenvolvimento Sustentável do Trópico Úmido, Universidade Federal do Pará, 2010.

BOURDIEU, Pierre. O poder simbólico. Rio de Janeiro: Editora Bertrand Brasil S.A, 1989.

DE CERTEAU, Michael. A invenção do cotidiano: artes de fazer. 3.ed. Petrópolis, RJ: Vozes, 1998.

CORNETTA, Andrei. Direitos territoriais nas várzeas de Breves, Marajó: novos usos da floresta e distintas percepções sobre o ambiente. Novos Cadernos NAEA, 19(2), 2016, p. 89-114.

Disponível em: https://periodicos.ufpa.br/index.php/ncn/article/view/2220.

DELGADO Lucíola de Almeida Neves. A história oral: memória, tempo, identidades. 2.ed. Belo Horizonte: Autêntica, 2010.

DIEGUES, Antônio Carlos Sant'Ana. O mito moderno da natureza intocada. 3. ed. São Paulo: Hucitec, 2001.

FREIRE, Paulo. Pedagogia do Oprimido. Rio de Janeiro: Paz e Terra, 2005.

FREIRE, Paulo. Pedagogia da autonomia. Rio de Janeiro: Paz e Terra, 2006.

FOUCAULT, Michael. Vigiar e punir: nascimento da prisão. 29.ed. Petrópolis, RJ: Vozes, 2004.

GALVÃO, Eduardo. Santos e visagens: um estudo da vida religiosa de Itá, Amazonas. Brasília: Brasiliana eletrônica, 1955.

HALL, Stuart. A identidade cultural na pós-modernidade. 11. ed. Rio de Janeiro: DP\&A., 2011.

HAGINO, Cora Hisae; QUINTANS, Mariana Trotta Dallalana. O reconhecimento de povos tradicionais e os usos contra-hegemônicos do direito no Brasil: entre a violência e a emancipação social. Revista Direito e Praxis, 6(10), 2015, p. 598-644. Disponível em: https://www.e-publicacoes.uerj.br/index.php/revistaceaju/article/view/15428.

HERRERA, José Antônio. Dinâmica e desenvolvimento da agricultura familiar: o caso de vila 
Amélia, Breves/Pará.120. Dissertação de Mestrado. Programa de Pós-Graduação em Agriculturas Familiares e Desenvolvimento Sustentável, Universidade Federal do Pará, 2003.

INSTITUTO BRASILEIRO DE GEOGRAFIA E ESTATÍSTICA. Censo demográfico 2010. Disponível em: https://cidades.ibge.gov.br/brasil/pa/breves/panorama.

LEITE, Etiene Lobato. Educação ambiental como instrumento de gestão na RESEX Mapuá: mediações para o desenvolvimento local. Dissertação de Mestrado. Programa de Pós-Graduação em Gestão de Recursos Naturais e Desenvolvimento Local na Amazônia, Universidade Federal do Pará, 2017.

MACHADO, Juliana. Salles. Lugares de gente: mulheres, plantas e redes de troca no delta amazônico. Tese de Doutorado. Programa de Pós-Graduação em Antropologia Socia, PPGAS/MN, Universidade Federal do Rio de Janeiro, 2011.

PAPA FRANCISCO. Carta encíclica Laudato Si' Do Santo Padre Francisco sobre o cuidado da Casa Comum, 2015. Disponível em: http:/_www.vatican.va/content/francesco/pt/encyclicals/ documents/papa-francesco_20150524_enciclica-laudato-si.html.

PACHECO, Agenor Sarraf. En el corazón de la Amazonia: identidade, saberes e religiosidade no regime das águas. Tese de Doutorado. Programa de Estudos Pós-Graduados em História, Pontifícia Católica de São Paulo, 2009.

PDSM. Plano de Desenvolvimento Territorial Sustentável para o Arquipélago de Marajó. Brasília, DF: Casa Civil. Belém-PA: Secretaria de Estado de Integração Regional, 2007.

PORTELLI, Alessandro. Tentando aprender um pouquinho: algumas reflexões sobre aética na História Oral. Proj. História, 15(1), 1997, p. 13-49. Disponível em: https:/ / revistas.pucsp. $\mathrm{br} / \mathrm{revph} / \mathrm{article} / \mathrm{view} / 11215 / 8223$.

RODRIGUES, Neidson. Educação: da formação humana à construção do sujeito ético. Educação E Sociedade, XXII(76), 2001, p. 232-257. Disponível em: https://www.scielo.br/pdf/es / v22n76/a13v2276.pdf.

SANTOS, Boaventura de Souza. Poderá o direito ser emancipatório? Revista Crítica de Ciências Sociais, 65, 2003, p. 3-76. Disponível em: http://www.boaventuradesousasantos.pt/ media/pdfs/podera_o_direito_ser_emancipatorio_RCCS65.PDF.

BRASIL. Para além do pensamento abissal: das linhas globais a uma ecologia de saberes. In: SANTOS, Boaventura e MENESES, Maria Paula (Orgs.). Epistemologia do Sul São Paulo: Cortez, 2010. pp. 31-83.

SCHAAN, Denise Pahl. Cultura Marajoara. Rio de Janeiro: Senac Nacional, 2009.

TOCANTINS, Leandro. O rio comanda a vida: uma interpretação da Amazônia. Rio de Janeiro: Biblioteca do Exército, 1973.

VIEIRA, Antônio. Cartas do Padre Antônio Vieira da Companhia de Jesus, tomo segundo, Lisboa Ocidental, officina da congregação do oratório, 1735. Disponível em: https:/ / www.livraria-trindade.pt/pt/produtos/ padre-antonio-vieira-cartas-tomo-segundo-lisboa-occidental-officina-da-congregacao-do-oratorio-1735.

\section{Fontes Orais}

Amarildo. 63 anos. Entrevista 1. [ago. de 2017]. Costa, Eliane M. Mapuá, Breves, PA, em $04 / 08 / 2017$.

Hozório. 53 anos. Entrevista 2. ago. de 2017. Costa, Eliane M. Mapuá, Breves, PA, em $12 / 08 / 2017$.

João. 58 anos. Entrevista 3. [ago. de 2017]. Costa, Eliane M. Mapuá, Breves, PA, em $12 / 08 / 2017$. 
Fernando. 58 anos. Entrevista 4. [ago. de 2017]. Costa, Eliane M. Mapuá, Breves, PA, em 19/08/2017.

Jovelino. 48 anos. Entrevista 5. [ago. de 2017]. Costa, Eliane M. Mapuá, Breves, PA, em 24/08/2017.

Ancelmo. 45 anos. Entrevista 6. [ago. de 2017]. Costa, Eliane M. Mapuá, Breves, PA, em 26/08/2017. 